\title{
Exploring the Role of Attitudinal Functions in Counterfeit Purchase Behavior via an Extended Conceptual Framework
}

\author{
Piyush Sharma ${ }^{1}$ \\ Ricky Y. K. Chan ${ }^{2}$
}

\section{Acknowledgments:}

This research was supported by Research Grant No. G-SAA9 awarded to the authors by The Hong Kong Polytechnic University, Hong Kong.

${ }^{1}$ Corresponding Author: Professor, School of Marketing, Curtin Business School, Curtin University, Bentley, WA 6102, Australia. Phone: +61 (8) 9266 3744, Fax: +61 (8) 92663937 (Email: piyush.sharma@curtin.edu.au)

${ }^{2}$ Associate Professor, Department of Management and Marketing, Faculty of Business, The Hong Kong Polytechnic University, Hung Hom, Kowloon, Hong Kong, Phone: +852-27667110, Fax: +852-2765-0611 (Email: ricky.yk.chan@polyu.edu.hk) 


\title{
Exploring the Role of Attitudinal Functions in Counterfeit Purchase Behavior via an Extended Conceptual Framework
}

\begin{abstract}
Prior research on counterfeit purchase behavior focuses on two attitudinal functions (social-adjustive and value-expressive) and ignores the others (e.g. egodefensive, knowledge and utilitarian), despite growing evidence that consumers' attitudes towards a product category may serve multiple functions. This paper addresses this research gap with an extended conceptual framework that incorporates all the five attitudinal functions and explores their direct and indirect effects on counterfeit product evaluation and purchase intention. A field study with 890 shoppers in Hong Kong, a popular market for both genuine and counterfeit brands, supports most hypotheses and provides useful insights into the complex socio-psychological mechanism driving counterfeit purchase behavior.
\end{abstract}

Keywords: attitudinal function; counterfeit; ego-defensive; involvement;

knowledge; social-adjustive; value-expressive 
Counterfeiting continues to be a growing problem around the world, estimated at about 5$7 \%$ of the total world trade and even up to $20 \%$ of domestic trade in countries such as China (Cesareo, 2016; Chaudhry, Cesareo, \& Stumpf, 2016). Interestingly, some consumers knowingly buy counterfeit products, despite the economic, performance and social risks attached with these (Amaral \& Loken, 2016; Bian et al., 2016; Rosenbaum, Cheng, \& Wong, 2016; Sharma \& Chan, 2016; Stöttinger \& Penz, 2015). Prior research uses diverse theoretical perspectives to explore the factors driving deliberate counterfeit purchase behavior, including economic, ethical and socio-psychological perspectives (See Sharma \& Chan, 2016 for a comprehensive review).

As pointed by Sharma and Chan (2016), early research explored the direct effects of consumer attitudes on counterfeit purchase behavior but ignored their interactions with each other and their combined influence, resulting in many mixed and inconclusive findings. For example, some studies found a positive effect of attitude towards counterfeiting on counterfeit purchase intentions (e.g., Maldonado \& Hume, 2005; Teah, Phau, \& Huang, 2015; Wee, Tan, \& Cheok, 1995) and actual purchase behavior (e.g., Penz \& Stöttinger, 2005). However, others found no effects of attitudes on either purchase intentions (e.g., Hoe, Hogg, \& Hart., 2003) or purchase behavior (e.g., de Matos, Ituassu, \& Rossi, 2007; Walthers \& Buff, 2008).

One of the reasons for these mixed findings could be that most of these studies focus on consumer attitudes towards counterfeit products and their direct effects on counterfeit product evaluation, purchase intentions or past purchase, and ignore the role of attitudes towards the product category and the functions served by these attitudes. Recent studies address this research gap by exploring the influence of two attitudinal functions (social-adjustive and valueexpressive) on counterfeit purchase behavior (Wilcox, Kim, \& Sen, 2009; Zampetakis, 2014). 
However, both of these studies focus on consumer attitudes towards luxury brands and ignore other product categories as well as other attitudinal functions (i.e., ego-defensive, knowledge and utilitarian), despite considerable evidence that consumer attitudes may serve multiple functions and some of these may even interact with each other (Czellar, 2003).

This paper addresses this research gap in two steps. First, the authors develop a basic conceptual framework to hypothesize the direct effects of all the five attitudinal functions (valueexpressive, social-adjustive, ego-defensive, knowledge and utilitarian) on counterfeit product evaluation and purchase intention (Figure 1). A field survey with 890 shoppers in Hong Kong (a popular market for both genuine and counterfeit brands) is used to collect data to test all these hypotheses. Next, the authors introduce three product characteristics (involvement, context and motivation) as moderators of the direct effects of some of the five attitudinal functions (Figure 2). These hypotheses are tested by comparing the direct effects of the five attitudinal functions across varying levels of the three product characteristics (involvement, context and motivation) using the data for the four counterfeit products (backpack, movie DVD, luxury watch and antivirus software) included in this study. Finally, the authors discuss the theoretical contribution and managerial implications of their findings along with the limitations of their research and some useful directions for future research.

\section{BASIC CONCEPTUAL FRAMEWORK}

\section{Consumer Attitudes towards Counterfeiting}

Early research identified attitude towards counterfeiting as an important driver of deliberate counterfeit purchase behavior. For example, Wee et al. (1995) show that consumers with 
unfavorable attitudes towards counterfeiting are less likely to purchase counterfeit products, such as books, software, leather wallets/purses and watches. Similarly, Ang et al. (2001) found 'attitude towards piracy' as a useful predictor of the purchase of pirated CDs. However, most of these studies focused on the cognitive and normative aspects of counterfeit purchase behavior, namely its acquisition utility, and ignored its affective and experiential aspects, also known as transactional utility. More recently, Sharma and Chan (2011) have introduced counterfeit proneness as a general tendency of consumers to prefer counterfeit over genuine products that taps into both transactional as well as acquisition utility associated with counterfeit purchase behavior. However, all these constructs tend to focus on the extrinsic motivations (e.g., economic benefit, perceived risk) and characteristics of counterfeit products (e.g., price, quality), and ignore the intrinsic aspects of how consumer attitudes towards a particular product category affect their evaluation and purchase of counterfeit products in that category.

In this context, recent research uses the functional theory of attitudes to investigate the impact of social-adjustive and value-expressive attitudinal functions on counterfeit purchase behavior. Specifically, it shows that consumers' preferences for a counterfeit luxury brand and the subsequent negative change in their preferences for the genuine brand are greater when their attitudes towards luxury brands serve a social-adjustive than a value-expressive function (Wilcox et al., 2009). In addition, moral beliefs about counterfeit consumption affect consumers' preference for counterfeits only when their luxury brand attitudes serve a value-expressive function. However, Wilcox et al. (2009) ignore other equally important attitudinal functions (i.e., ego-defensive, knowledge and utilitarian) despite their influence on consumer behavior in areas such as advertising (Shavitt, Lowrey, \& Han, 1992; Sirgy et al., 1991), consumer choice and 
store environment (Schlosser, 1998). Next, this paper describes all the five attitudinal functions and then hypothesizes their influence on counterfeit product evaluation, and purchase behavior.

\section{Functional Theory of Attitudes (Attitudinal functions)}

Consumer attitudes towards various objects serve a variety of functions that direct and facilitate their behavior (Eagly \& Chaiken, 1998; Katz, 1960; Locander \& Spivey, 1978; Smith, Bruner, \& White, 1956). Smith et al. (1956) and Katz (1960) conceptualized a functional approach to address the motivational foundations for people's attitudes and their functional orientations. Specifically, Smith et al. (1956) introduced three attitudinal functions: object appraisal, externalization and social adjustment, whereas Katz (1960) introduced four attitudinal functions: knowledge, utilitarian, value-expressive and ego-defensive functions.

Most attitudes serve a basic knowledge function that helps consumers organize, structure, and summarize large amounts of complex information about attitude objects in the environment and provides consistency in their frames of reference (Fazio, Powell, \& Williams, 1989). Such attitudes help consumers make quick decisions without referring to all the specific information that may have used initially as a basis to form their attitudes. In contrast, attitudes serving the value-expressive function help consumers express their central values, idiosyncratic preferences, and self-perceptions to others, which facilitates interpersonal communication and identify like-minded consumers (Katz, 1960; Shavitt, 1990). Attitudes serving ego-defensive function help individuals maintain their self-esteem and cope with anxieties from internal conflicts. Smith et al. (1956) call this externalization function, in which people are shown to use defense mechanisms such as denial, repression and projection to protect them against threats 
from their internal and external environments (Eagly \& Chaiken, 1993). Attitudes that serve the utilitarian or instrumental function help consumers maximize rewards and minimize punishment from objects in their environment (Herek, 1987; Katz, 1960). Finally, social-adjustive function helps consumers identify with reference groups and conform to others' expectations in order to ensure smooth and efficient social interactions (Smith et al., 1956; Snyder \& DeBono, 1989).

Attitudinal functions help explain why people possess different attitudes toward the same object because an attitude can serve different functions and different attitudinal functions may even interact with each other (Locander \& Spivey, 1978), although in most cases a particular function may dominate (Shavitt, 1989, 1990). Therefore, marketers generally find it useful to identify the dominant function for a particular consumer segment in order to highlight its appeal in their communication (Schlosser, 1998). In fact, even academic researchers tend to focus on only a few attitudinal functions and their independent effects to avoid complexity in their research. For example, some show that ads relevant to a particular attitudinal function generate more favorable thoughts and preference for the ad and the advertised product or service (Johar \& Sirgy, 1991). Similarly, attitudes serving the social-identity function may influence innovativeness and opinion leadership (Grewal, Mehta, \& Kardes, 2000) and different types of attitudinal functions may affect the timing of consumer goods repeat purchase (Grewal, Mehta, \& Kardes, 2004).

\section{Attitudinal functions and Counterfeit Consumption}

\section{Value-Expressive Function (AVE)}


Value-expressive attitudes help consumers express their central values and self-concept to others around them, and develop activities, interests, and opinions that depict a particular social identity (Katz, 1960; Shavitt, 1990). Under the influence of these attitudes, consumers make consumption decisions based on their self-identity and their expectations of how others will react to their purchase decisions (Shavitt, 1990; Snyder \& DeBono, 1989). In other words, under such situations consumers may feel obliged to explain or justify their product-related choices and decision to others around them. With an increase in the extent to which an attitude serves the value-expressive function, consumers need to justify their decisions to others may also increase, making them behave in a more socially desirable manner.

Prior research shows that consumers are more responsive to messages that promote intrinsic functional attributes of products, such as quality or reliability, when they hold attitudes serving a value-expressive function because such messages are more readily interpretable in terms of their underlying values and dispositions (Snyder \& DeBono, 1985). In the context of counterfeit products, prior research shows that consumers with strong value-expressive attitudes towards genuine brands have relatively more negative attitudes and lower preference towards counterfeit products (Wilcox et al., 2009). Hence, the following hypothesis:

H1: Value-expressive attitudinal function served towards a product category has a negative effect on the evaluation of a counterfeit product in that category.

\section{Social-adjustive Function (ASA)}

Attitudes serving a social-adjustive function help people maintain social relationships and to gain approval from others in social situations (Smith et al., 1956; Snyder \& DeBono, 1989). Recent 
research shows that consumers' preference for counterfeits and negative change in their preferences for the genuine brand are greater when their attitudes towards luxury brands serve a social-adjustive function (Wilcox et al., 2009). Hence, consumers whose attitudes towards genuine brands serve a social-adjustive function are likely to have positive attitudes towards counterfeit products as these may allow them to make a good impression in social situations if others are not able to distinguish them from genuine products. Therefore, as follows:

H2: Social-adjustive attitudinal function towards a product category has a positive effect on the evaluation of a counterfeit product in that category.

\section{Ego-Defensive Function (AED)}

Attitudes that help protect an individual from external threats or internal feelings of insecurity, perform an ego-defensive function (Locander \& Spivey, 1978). Besides acting as a mechanism for adjusting or avoiding internal and external difficulties, these attitudes also help defend a person's self-image through objects selected as a convenient outlet to express their personal identity (Hogg \& Abrams, 1988). Ego-defensive function is affected to a greater extent by external influences, such as peer groups and social trends, reflecting a desire to project an image to the outside world (Kardes, 2002). Thus, ego-defensive function seems to be more oriented toward what others value, not what the individual values. Ego-defensive function is observed when the consumers buy a brand to enhance their self-esteem or boost their ego. Messages about high-ego related issues (or products) threaten a consumer's ego may be discounted by the consumers (Lapinski \& Boster, 2001). Similarly, Korgaonkar, Lund, and Price (1985) found a positive relationship between ego-defensive function and store preference. Marketers generally 
use situations involving social embarrassment to highlight how their product or service may help the consumers avoid being in such a situation and thus serve an ego-defensive function.

In the counterfeit context, as well-known genuine brands are mostly used to improve one's self-image, using their counterfeit versions may actually defeat this purpose, especially for those consumers whose attitudes towards genuine brands serve ego-defensive function. As a result, consumers with attitudes towards a product category serving ego-defensive function, may have less favorable evaluation and purchase intention for counterfeit products, in order to avoid losing face if they are found favoring or using such products. Hence, as follows:

H3: Ego-defensive attitudinal function towards a product category has a negative effect on the evaluation of a counterfeit product in that category.

\section{Knowledge Function (AKN)}

Attitudes serving the knowledge function help consumers organize and categorize their worlds in a meaningful and consistent manner in order to provide order, clarity, and consistency in their frames of reference (Herek, 1987). Consumers with more knowledge about a product category are likely to use well-defined criteria in their decision-making and judgments across diverse contexts (Bettman, Luce, \& Payne, 1998). High knowledge consumers are less likely to be affected by context effects and more likely to make satisfying product choices. Consumers with attitudes towards a product category serving knowledge function may have more knowledge about both genuine brands and their counterfeit versions and greater confidence in being able to distinguish between a genuine brand and its counterfeit version (Penz \& Stöttinger, 2008a). In 
fact, this ability to distinguish between the genuine brands and their counterfeit versions would make the consumers evaluate the counterfeit products unfavorably. Hence,

H4: Knowledge attitudinal function towards a product category has a negative effect on the evaluation of a counterfeit product in that category.

\section{Utilitarian Function (AUT)}

Utilitarian function relates to the basic principles of reward and punishment, wherein people develop attitudes on the basis of whether a product or service provides pleasure or pain. Attitudes serving utilitarian function are linked to consumers' self-interest and help them draw maximum benefits from their consumption experiences (Herek, 1987; Shavitt, 1989, 1990). Attitudes serving utilitarian function result in the product or service being perceived as a means to an end (extrinsic motivation) while the intrinsic or hedonic factors such as appearance, style, prestige and esteem are less relevant. However, strength of utilitarian attitudes may vary with product type (Eagly \& Chaiken, 1998; Krosnick \& Petty, 1995).

Consumers with attitudes towards a product category serving a utilitarian function are likely to experience similar benefits from using a counterfeit product as that from a genuine brand and they may even perceive both these types of products to be quite similar. As a result, these consumers may develop a positive attitude towards the counterfeit product and possibly an unfavorable opinion about the genuine brand because of its poor utilitarian value (due to a much higher price with similar functional utility). Based on this, a positive effect of utilitarian attitudinal function on the evaluation of a counterfeit product is hypothesized, as follows: 
H5: Utilitarian attitudinal function towards a product category has a positive effect on the evaluation of a counterfeit product in that category.

[Insert Figure 1 about here]

Figure 1 summarizes the basic conceptual framework with these five hypotheses about the direct effects of the five attitudinal functions towards a specific product category on the evaluation of counterfeit products in that category. The next section describes a field-survey based study conducted with shoppers in Hong Kong to test all these hypotheses.

\section{METHOD}

\section{Sample and Procedure}

A field-survey was conducted by a team of ten well-trained student helpers who recruited shoppers in major shopping areas of Hong Kong and collected 890 complete questionnaires, with a response rate of about $30 \%$, which is reasonably high for surveys using similar mall-intercept approach (Bush \& Hair Jr., 1985). Each participant was given a HK\$ 20 coupon (about USD 2.50), which could be redeemed at all the branches of a local Fast-food chain. The survey team was not told the actual research objectives and hypotheses in order to minimize the effect of demand effects. The survey was conducted during shopping hours throughout the week and not during any special festivals or holidays to ensure a fair representation of the target population.

Hong Kong was chosen as the research setting for this study because of the wide-spread availability, popularity and frequent usage of counterfeit goods, locally as well as in nearby Chinese cities (Cheung \& Prendergast, 2006a, 2006b; Harvey \& Walls, 2003; Sharma \& Chan, 
2011). Hong Kong is also an entry port for counterfeit goods in and out of China, which is the world's biggest producer and consumer of counterfeit products (Chow, 2005; Yao, 2006). Not surprisingly, China and Hong Kong are the major countries of origin for two-thirds (67\%) of the total reported cases in a recent report by World Customs Organization on counterfeit goods caught by customs authorities in its 58 member countries in 2012 (WCO, 2014).

[Insert Table 1 about here]

As shown in Table 1, the sample has more females (53\%) than males as well as relatively younger $(87 \%, \leq 40$ years $)$ and better educated $(72 \%,>$ High School) participants compared to the general population in Hong Kong (HKCSD, 2013). Interestingly, 62\% of the participants have purchased counterfeit products in the past and 34\% in the past three months. Hence, this sample seems appropriate for studying the influence of different types of functions served by attitudes towards specific product categories on the evaluation and purchase intention for counterfeit products in those categories.

To select the product categories, the authors used a pre-test with 60 consumers with similar profile as the participants in the main study. These consumers rated 30 commonly counterfeited product categories on three popular characteristics used in prior research (i.e., involvement level, consumption context and purchase motivation) along with product familiarity and relevance. Based on their high scores on product familiarity and relevance, four product categories were chosen and coded for involvement $(0=$ low; $1=$ high $)$, consumption context $(0=$ private; $1=$ public $)$ and motivation $(0=$ hedonic; $1=$ utilitarian $)$, as follows:

- Luxury watch (high involvement, public consumption, hedonic motivation) 
- Anti-virus software (high involvement, private consumption, utilitarian motivation)

- Movie DVD (low involvement, private consumption, hedonic motivation)

- Backpack (low involvement, public consumption, utilitarian motivation)

All the participants were randomly assigned to one of these four product categories and they completed a structured questionnaire with three sections. In the first section, they responded to four-item scales for the five attitudinal functions (value-expressive, social-adjustive, egodefensive, knowledge and utilitarian) towards the product category, adapted from existing scales (Grewal et al., 2004; Wilcox et al., 2009), along with counterfeit proneness scale (Sharma \& Chan, 2011). Next, they recorded their ethical judgment and subjective norms (Sharma \& Chan, 2012) as well as product evaluation and purchase intention (de Matos et al., 2007) for counterfeit product in the same category. All these scales used seven-point Likert-type response formats $(1=$ strongly disagree, $7=$ strongly agree $)$ except purchase intention $(1=$ very unlikely, $7=$ very likely). Finally, their past purchase of counterfeit products, frequency of purchase in last three months and demographics (age, gender, education, and occupation) were recorded.

\section{DATA ANALYSIS AND RESULTS (PART I)}

The well-established two-step procedure was used to analyze the data using Structural Equation Modeling (SEM) with AMOS 22.0 (Anderson \& Gerbing, 1988; Byrne, 2004). Confirmatory factor analysis (CFA) on all the scales shows a good fit $\left(\chi^{2}=1183.73, \mathrm{p}<.001 ; \mathrm{df}=677, \chi^{2} / \mathrm{df}=\right.$ $1.75 ; \mathrm{GFI}=.95, \mathrm{NFI}=.95, \mathrm{CFI}=.97, \mathrm{RMSEA}=.029$, and $\mathrm{SRMR}=.036)$. All the fit parameters are better than the cut-off values (RMSEA $<.06$, SRMR $<.08$, CFI $>.95)$ advised by $\mathrm{Hu}$ and Bentler (1999) and $\left(1<\chi^{2} / d f<3\right)$ proposed by Wheaton et al. (1977). Table 2 shows the 
psychometric properties of all the scale items, including standardized factor loadings, squared multiple correlations, and descriptives (mean and standard deviation).

[Insert Table 2 about here]

All the parameter estimates $(\lambda)$ have significantly large t-values (11.35-28.23) and all squared multiple correlations (.51-.75) and average variance extracted (.55-.70) are higher than .50, showing high convergent validity (Fornell \& Larcker, 1981). Average variance extracted for each factor exceeds its squared correlations with all the other factors, showing discriminant validity (Fornell \& Larcker, 1981). As shown in Table 3, all the independent variables are only moderately correlated with each other (highest correlation coefficient, $r=.52$ ).

[Insert Table 3 about here]

Next, a hierarchical regression modeling approach was used with the pooled data from all the four product categories by entering blocks of independent variables to test their incremental impact on counterfeit product evaluation (CPE). As shown in Table 4, Model 1 with all the control variables shows a significant fit $\left(\operatorname{adj} . \mathrm{R}^{2}=.05, \mathrm{~F}=5.85, \mathrm{p}<.001\right)$ to the data. All the control variables have significant effects on counterfeit product evaluation, including counterfeit proneness $(\beta=.27, \mathrm{p}<.001)$, ethical judgments $(\beta=.23, \mathrm{p}<.001)$, subjective norms $(\beta=.28, \mathrm{p}<$ $.001)$, involvement $(\beta=.17, \mathrm{p}<.05)$, consumption context $(\beta=-.23, \mathrm{p}<.001)$ and purchase motivation $(\beta=.09, \mathrm{p}<.05)$. However, all of these explain only $5 \%$ overall variance in overall counterfeit product evaluation.

[Insert Table 4 about here] 
Next, entering the direct effects of the five attitudinal functions (Model 2) shows a significant (p $<.001$ ) improvement in the fit (adj. $\left.\mathrm{R}^{2}=.13, \mathrm{~F}=8.72, \mathrm{p}<.001\right)$. As shown in Table 4, valueexpressive $(\beta=-.24, \mathrm{p}<.001)$, ego-defensive $(\beta=-.15, \mathrm{p}<.01)$ and knowledge $(\beta=-.21, \mathrm{p}<$ .01) attitudinal functions have significant negative effects, and utilitarian function has a positive effect $(\beta=.32, \mathrm{p}<.001)$ on counterfeit product evaluation, thus $\mathrm{H} 1, \mathrm{H} 3, \mathrm{H} 4$ and $\mathrm{H} 5$ are supported. However, social-adjustive function has an unexpected strong negative effect ( $\beta=-.61$, $\mathrm{p}<.001$ ) on counterfeit product evaluation, hence $\mathrm{H} 2$ is not supported.

From these findings, it seems that the direct effects of all the five attitudinal functions (along with all the control variables) can only explain a relatively small proportion (13\%) of the total variance in the overall counterfeit product evaluation in the data. Hence, it is clear that there is need to use the indirect effects of these attitudinal functions to extend the basic conceptual model, to be able to explain a significantly greater proportion of variance in the dependent variables, namely counterfeit product evaluation and purchase intention. In the next section, the authors extend their basic model by arguing that three product characteristics (involvement level, consumption context and purchase motivation) moderate some of the effects of the five attitudinal functions on counterfeit product evaluation, which in turn mediates the direct and indirect effects of the five attitudinal functions on counterfeit purchase intention.

\section{EXTENDED CONCEPTUAL FRAMEWORK}

\section{Involvement Level (INV)}

Consumers differ in the extent of search and processing of information depending on their level of involvement for different product categories and it affects their attitudes and behavior from 
one consumption situation to another (Laurent \& Kapferer, 1985; Mittal, 1989; Zaichkowsky, 1985). However, in the counterfeit context, there is mixed evidence about the direct effects of product involvement, knowledge and familiarity, with some showing a negative effect on counterfeit purchase behavior (d'Astous \& Gargouri, 2001) and others showing no significant effect (Bian \& Moutinho, 2009, 2011). Involvement moderates processes such as advertising effectiveness (Petty, Cacioppo, \& Schumann, 1983), attention and comprehension (Celsi \& Olson, 1988), persuasion (Miniard et al., 1991), repurchase loyalty (Olsen, 2007), service evaluation (Chen \& Tsai, 2008) and online knowledge sharing (Chang \& Chuang, 2011). Consumers use an elaborate central processing style under high involvement and search for more information; and a peripheral style under lower involvement with simple heuristic cues with little or no active search for information (Petty et al., 1983).

Prior research on attitudinal functions shows that their influence may vary across product categories such as luxuries vs. necessities and those meant for private vs. public consumption, due to differences in the information processing styles used by consumers (Grewal et al., 2004). In this context, involvement level may also moderate the effect of attitudinal functions on the evaluation and purchase intention for a counterfeit product. Specifically, under lower involvement, consumers may use simple cues such as lower price and similarity between the counterfeit and its genuine version due to lower perceived risk, which may reduce the impact of attitudinal functions on counterfeit product evaluation. In contrast, under higher involvement, consumers may seek more information such as the quality and performance of the counterfeit product and rely to a greater extent on their attitudes serving the knowledge and utilitarian functions in this process. Based on the above, the following hypothesis is put forth: 
H6: Involvement level moderates the effects of attitudinal functions on the evaluation of a counterfeit product; such that, a) the negative effect of knowledge function and b) the positive effect of utilitarian function, are stronger for high (vs. low) involvement products.

\section{Consumption Context (CON) - Private vs. Public}

Consumers purchase and use brands to convey an image to themselves and others (Belk, 1988); and they are also more concerned about social norms in public (vs. private) situations (Ariely \& Levav, 2000; Choi et al., 2006). In fact, attitudes about the public/private character of a product category also affect the degree of normative influences on their purchase and consumption (Bearden \& Etzel, 1982; Fisher \& Price, 1992). Social influence also has a stronger impact on adoption of high-tech innovations under public (vs. private) consumption because it helps consumers make a positive impression on their significant others (Kulviwat, Bruner II, \& AlShuridah, 2009). Similarly, cultural factors such as power distance and masculinity have stronger influence on evaluation and purchase of imported products used in public (Sharma, 2011b).

Consumers are more likely to purchase counterfeit products for consumption in public (vs. private) despite a greater social risk of losing face if they are found out (Chapa, Minor, \& Maldonado, 2006). One reason for this paradox may be that consumption context does not affect counterfeit consumption directly and moderate the effect of attitudinal functions instead (Grewal et al., 2004). As shown by Wilcox et al. (2009), consumer attitudes serving social-adjustive function have a stronger impact compared to those serving value-expressive function, on their preference for counterfeit luxury brands, possibly because luxury products are generally used in 
public and they help the consumers project a certain image and make a good impression on their significant others. In contrast, Grewal et al. (2004) show that the effect of value-expressive attitudinal function is more pronounced for products used in private (vs. public) because they may focus more on the intrinsic benefits of the product such as product quality rather than their social appeal. Based on this reasoning, the following hypothesis is proposed:

H7: Consumption context moderates the effect of attitudinal functions on counterfeit product evaluation; such that, a) the negative effect of value-expressive function is stronger for products used in private (vs. public), whereas b) the positive effect of social-adjustive function is stronger for products used in public (vs. private).

\section{Purchase Motivation (MOT) - Hedonic vs. Utilitarian}

Consumer motivations vary for purchasing different types of products. While hedonic products help them satisfy their desires for sensory pleasure and their symbolic needs, utilitarian products generally satisfy practical or functional needs (Holbrook \& Hirschman, 1982). Hedonic goods (e.g., flowers, designer clothes, music, luxury watches, sports cars, and chocolates) are multisensory and provide experiential consumption for fun, pleasure, and excitement; whereas, utilitarian goods (e.g., household appliances, detergents, and personal computers) mostly provide functional utility (Dhar \& Wertenbroch, 2000). Therefore, the evaluation process for hedonic products is generally more subjective and affect-driven compared to the primarily cognitive evaluation process for utilitarian products (Holbrook \& Moore, 1981). Prior research on attitudinal functions also shows differences in their impact on luxuries and necessities (Grewal et al. 2004). 
Wilcox et al. (2009) demonstrate that the social-adjustive function served by attitudes toward luxury brands has a stronger impact compared to their value-expressive function, on their preference for counterfeit luxury brands, although consumers' moral beliefs have a stronger impact when the attitudes serve a value-expressive function. Interestingly, Grewal et al. (2004) argue that the effect of attitudes serving knowledge and utilitarian functions is stronger for luxury products compared to necessities, because luxury products are more exclusive, arouse greater affect and provide multiple benefits compared to necessities. Based on the above, valueexpressive and social-adjustive functions may play a greater role in the evaluation of hedonic counterfeit products because of the greater affective associations and complex underlying motivations for hedonic products (Holbrook \& Moore, 1981). In contrast, knowledge and utilitarian functions may have a stronger impact on the evaluation of utilitarian products because of the greater emphasis on tangible attributes and functional benefits for such products (Holbrook \& Moore, 1981). Hence, the following hypothesis:

H8: Purchase motivation moderates the effects of attitudinal functions on counterfeit product evaluation; such that, the effects of a) value-expressive and b) socialadjustive functions are stronger for hedonic (vs. utilitarian) products and the effects of c) knowledge and d) utilitarian functions are stronger for utilitarian (vs. hedonic) products.

\section{Counterfeit product evaluation (CPE) and purchase intention (CPI)}

Prior research shows mixed results about the effects of antecedents such as consumer attitudes, ethical judgments and subjective norms on counterfeit purchase behaviour and intentions. For 
example, some studies show a positive effect of attitude towards counterfeiting on purchase intentions (e.g., Maldonado \& Hume, 2005; Wee, Tan, \& Cheok, 1995) and actual purchase behaviour (e.g., Penz \& Stöttinger, 2005) whereas others show either no effect on purchase intentions (e.g., Hoe, Hogg, \& Hart., 2003) or past purchase (e.g., de Matos, Ituassu, \& Rossi, 2007; Walthers \& Buff, 2008) or even a negative effect (Stöttinger \& Penz, 2015).

One of the main reasons for these mixed findings could be that these studies explore the 'direct' effects of various antecedents on counterfeit purchase intentions and ignore the mediating influence of 'product evaluation', despite its importance in predicting purchase intentions (Dodds, Monroe, \& Grewal, 1991; Sharma, 2011a, 2011b). Specifically, irrespective of the function served by the customers' attitudes towards a product category, they may not want to buy a particular counterfeit product due to other reasons such as product quality, price difference vis-à-vis its genuine version etc. Based on this, it is hypothesized that the evaluation of a counterfeit product would mediate the direct and indirect influence of all the attitudinal functions on consumers' intention to purchase a counterfeit product in that category.

H9: Counterfeit product evaluation mediates the direct and indirect influence of all the attitudinal functions on the purchase intention for a counterfeit product.

\section{[Insert Figure 2 about here]}

Figure 2 shows the extended conceptual framework with the additional hypotheses about the moderating effects of the five attitudinal functions and the mediating role of product evaluation in the process by which the five attitudinal functions influence counterfeit purchase intention. In the next section, the authors describe their findings about all these hypotheses. 


\section{DATA ANALYSIS AND RESULTS (PART II)}

The authors continued with their hierarchical regression analysis reported in Part I of their data analysis and added the interactions between the three product characteristics and the five attitudinal functions as hypothesized in H6-H8. This model (Model 3) shows a significantly better $(\mathrm{p}<.001)$ fit to the data $\left(\operatorname{adj} . \mathrm{R}^{2}=.30, \mathrm{~F}=16.37, \mathrm{p}<.001\right)$ compared to both Model 1 and 2, with most of the hypothesized effects as statistically significant and in the expected directions.

\section{[Insert Table 4 about here]}

As expected, involvement shows a significant negative interaction with knowledge function $(\beta=-.24, \mathrm{p}<.001)$ and a positive interaction with utilitarian function $(\beta=.14, \mathrm{p}<.01)$, hence both H6a and H6b are supported. Similarly, consumption context has a significant negative interaction of value-expressive function $(\beta=-.26, p<.001)$ and a positive interaction with social-adjustive function $(\beta=.11, \mathrm{p}<.01)$, hence $\mathrm{H} 7 \mathrm{a}$ and $\mathrm{H} 7 \mathrm{~b}$ are also supported. Next, the interaction of purchase motivation with value-expressive function is not significant $(\beta=.08, p>$ .10) and is opposite to the hypothesized direction with knowledge function $(\beta=-.11, p<.05)$, hence $\mathrm{H} 8 \mathrm{a}$ and $\mathrm{H} 8 \mathrm{c}$ are not supported. However, purchase motivation has a significant negative interaction with social-adjustive function $(\beta=-.19, \mathrm{p}<.01)$ and a positive interaction with utilitarian function $(\beta=.28, \mathrm{p}<.001)$, hence $\mathrm{H} 8 \mathrm{~b}$ and $\mathrm{H} 8 \mathrm{~d}$ are also supported.

Finally, the three-step method recommended by Baron and Kenny (1986) was used to test the mediating role of counterfeit product evaluation. First, as described above, Model 3 shows that all the five attitudinal functions and most of their hypothesized interactions with the three product characteristics as independent variables have significant effects on counterfeit product 
evaluation (the mediator). Next, Model 4 with all the five attitudinal functions and their hypothesized interactions with the three product characteristics as independent variables and the counterfeit purchase intention as the dependent variable shows a good fit to the data $\left(\operatorname{adj} . \mathrm{R}^{2}=\right.$ $.36, \mathrm{~F}=19.68, \mathrm{p}<.001)$. Most of the independent variables have significant effects on purchase intentions, as shown in Table 4. Finally, Model 5 with all the independent variables (five attitudinal functions and their interactions) and the mediators (counterfeit product evaluation) shows the best fit among all the models (adj. $\left.\mathrm{R}^{2}=.42, \mathrm{~F}=21.29, \mathrm{p}<.001\right)$. Moreover, the effects of most independent variables on the dependent variable (counterfeit purchase intention) become non-significant in the presence of the mediator (counterfeit product evaluation). Hence, counterfeit product evaluation partially mediates the effects of the five attitudinal functions on counterfeit purchase intention, thus showing only partial support for H9.

\section{GENERAL DISCUSSION}

This paper looks beyond the traditional socio-psychological and ethical perspectives of counterfeit purchase behavior and uses functional theory of attitudes (Katz, 1960) to develop an extended conceptual framework about the role of attitudinal functions in counterfeit purchase behavior. Specifically, this paper explores the effects of five attitudinal functions (valueexpressive, social-adjustive, ego-defensive, knowledge and utilitarian) on the evaluation and purchase intention for four types of products that vary from each other in terms of three product characteristics (involvement level, consumption context and purchase motivation). Combining all the five attitudinal functions with these three product characteristics provides a deeper and more nuanced view about the impact of attitudinal functions in the counterfeit context. In fact, including the direct and indirect effects of attitudinal functions in the model helps explain 
significantly greater variance $(30 \%)$ in the data compared to the other predictors used in past research, such as counterfeit proneness, ethical judgments, subjective norms and product characteristics (5\%). In addition, using counterfeit product evaluation as a mediator helps explain $42 \%$ variance in counterfeit purchase intention, which is much higher than the variance explained in most prior studies on counterfeit purchase behavior. Hence, the new extended conceptual framework presented in this paper provides incremental insights into the complex socio-psychological decision-making process underlying counterfeit product evaluation and purchase intentions.

Ten out of fourteen hypotheses find full support and one finds partial support. First, the results show that, besides the value-expressive and social-adjustive attitudinal functions as shown by Wilcox et al. (2009), ego-defensive, knowledge and utilitarian functions also affect the evaluation of counterfeit products. As hypothesized, value-expressive, ego-defensive and knowledge functions have negative effects and utilitarian function has a positive effect on counterfeit product evaluation. However, social-adjustive function has an unexpected negative effect instead of the hypothesized positive effect based on (Wilcox et al., 2009). A closer look shows that Wilcox et al. (2009) focus on luxury products that are generally hedonic in nature and are used in public; whereas this study included four types of products including both hedonic and utilitarian products as well as those used in private and public. Moreover, Wilcox et al. (2009) explore the influence of attitudinal functions on 'preference' for counterfeit luxury brands and not on their 'evaluation'. Hence, it seems that this paper captures a broader and more 'natural' negative effect of social-adjustive function rather than a more 'product-specific' positive effect found by Wilcox et al. (2009). In other words, it is more likely in general that social-adjustive 
functions served by attitudes towards a product category would dissuade consumers from evaluating counterfeit products more favorably and thus show a negative effect on counterfeit product evaluations, similar to value-expressive, ego-defensive and knowledge functions.

These findings extend the growing research on the impact of attitudinal functions on consumers in diverse contexts, such as advertising (Johar \& Sirgy, 1991; Shavitt, 1990; Shavitt et al., 1992; Shavitt \& Nelson, 2002; Spivey, Munson, \& Locander, 1983), consumer choice (Allen, $\mathrm{Ng}$, \& Wilson, 2002), consumer innovativeness and opinion leadership (Grewal et al., 2000), store image and patronage (Korgaonkar et al., 1985; Schlosser, 1998) etc. This paper also highlights the need to study the impact of a wider range of attitudinal functions on consumer behavior as most attitudes serve multiple functions (Locander \& Spivey, 1978). Moreover, consumers are influenced by more than one type of motivation, hence there is need to study not only the individual but also combined effect of attitudinal functions (Katz, 1960).

Finally, this paper also extends prior research on the moderating impact of product characteristics on the influence of multiple attitudinal functions, such as Grewal et al.'s (2004) work on inter-purchase interval using private vs. public and luxury vs. necessity distinction among product categories. In fact, this paper provides a more complete approach by using three distinct characteristics, namely involvement level, consumption context and purchase motivation, to distinguish the product categories. For example, this study shows that involvement level has contrasting moderating effects on the impact of knowledge (negative) and utilitarian (positive) functions; while consumption context has similar contrasting moderating effects on the influence of value-expressive (negative) and social-adjustive (positive) functions respectively. These 
findings provide new insights into the roles of attitudinal functions in counterfeit purchase behavior and into the differences in counterfeit purchase behavior across product categories.

The results of this study also show that counterfeit product evaluations partially mediate the direct and indirect effects of all the five attitudinal functions and all the control variables, including the three product characteristics. This is an important finding because prior research on counterfeit purchase behavior has generally ignored the role of biased evaluations of counterfeit products (Sharma and Chan 2016). This study shows that consumer attitudes towards a product category and the functions served by these attitudes may only influence their evaluations of counterfeit products in those categories and not their purchase intentions, which may depend on other factors such as product quality, price, packaging and even perceived similarity between the counterfeit product and its genuine version.

This study found only mixed evidence on the moderating effect of purchase motivation; wherein social-adjustive function has a stronger effect for hedonic products and utilitarian function on the utilitarian products but the value-expressive function does not show any significant difference between hedonic and utilitarian products, whereas knowledge function shows a stronger effect on hedonic product. Wilcox et al. (2009) argue that moral beliefs about counterfeit consumption only have an impact on brand preference if the attitudes toward luxury brands serve value-expressive function. The use of multiple product categories in this study may have reduced the impact of value-expressive function and this may have led to these nonsignificant findings. In addition, the knowledge function may have enhanced the perceived similarity between the counterfeit hedonic products and their genuine versions and this may have resulted in the opposite findings to what was expected. 
Notwithstanding some non-significant findings, this research has many important managerial implications. First, it shows that consumer attitudes towards a product category may not only serve more than one function but these functions may also interact with characteristics of the product category. Marketing managers can use these findings to identify those attitudinal functions that may be more relevant to their product categories and emphasize those in their communication and promotion strategies. For example, if a product category elicits greater value-expressive attitudes that reduce the preference for counterfeits to some extent, then marketers may be able to curb the favorable evaluations and purchase intentions of counterfeit products in this category, by increasing their emphasis on the ego-defensive and knowledge functions in their advertising and other communications. This may help them leverage the combined impact of these different attitudinal functions in reducing counterfeit purchases.

This study also found some differences in the influence of the attitudinal functions and their interactions across different product categories with varying levels of product involvement, consumption context and purchase motivations. For example, products used in public have a stronger negative impact of social-adjustive function on their counterfeit product evaluation and purchase intention. Marketers can use these findings to identify and reinforce those attitudinal functions that are more likely to influence the consumers for their product categories. For instance, marketers of cosmetic or jewelry products may find that social-adjustive and valueexpressive function have a stronger impact on the demand and preference for their products because of consumers' concerns about how they look. In contrast, marketers of books, software and medicines may find a greater role of knowledge and utilitarian functions. Therefore, all these 
marketers can use more of the relevant appeals in their advertising to not only promote their products but also deter consumers from buying counterfeit products in these categories.

\section{LIMITATIONS AND FUTURE RESEARCH}

This research has a few limitations. First, this study was conducted in Hong Kong, a popular market for counterfeits with easy availability and regular usage of counterfeit goods. Moreover, Hong Kong is dominated by the Chinese culture and this may influence the attitudes and behaviors of consumers in Hong Kong. Hence, it would be useful to conduct similar research in other parts of the world such as North America, Europe, and rest of Asia, where counterfeiting is not so common and which represent other cultural values. This would help validate the role of various attitudinal functions in the counterfeit purchase and consumption in more culturally and socio-economically diverse environments. Second, this study included several control variables, including counterfeit proneness, ethical judgments and subjective social norms. Future research could integrate these variables to develop an even more comprehensive conceptual framework or include other psychographic variables such as innovativeness, risk-taking and change-seeking, to explore their influence on counterfeit purchase behavior and usage. Third, the mixed results about the influence of social-adjustive function could be due to the choice of products included in this study, which may also be addressed by future researchers by using other product categories in their studies. Finally, this paper does not explore the interactions among the five attitudinal functions for parsimony; however, future research may examine these interactions by developing specific a-priori hypotheses and testing these with empirical data. 


\section{REFERENCES}

Albers-Miller, N. D. (1999). Consumer misbehavior: Why people buy illicit goods? Journal of Consumer Marketing, 16(3), 273-287.

Allen, M. W., Ng, S. H., \& Wilson, M. (2002). A functional approach to instrumental and terminal values and the value-attitude-behaviour system of consumer choice. European Journal of Marketing, 36(1/2), 111-135.

Amaral, N. B., \& Loken, B. (2016). Viewing usage of counterfeit luxury goods: Social identity and social hierarchy effects on dilution and enhancement of genuine luxury brands. Journal of Consumer Psychology. doi:http://dx.doi.org/10.1016/j.jcps.2016.02.004

Anderson, J. C., \& Gerbing, D. W. (1988). Structural equation modeling in practice: A review and recommended two step approach. Psychological Bulletin, 103(3), 411-423.

Baron, R. M., \& Kenny, D. A. (1986). The Moderator-Mediator Variable in Social Psychological

Research: Conceptual, Strategic and Statistical Considerations. Journal of Personality and Social Psychology, 51(6), 1173-1182.

Bettman, J. R., Luce, M. F., \& Payne, J. W. (1998). Constructive Consumer Choice Processes. Journal of Consumer Research, 25(3), 187-217.

Bian, X., Wang, K.-Y., Smith, A., \& Yannopoulou, N. (2016). New insights into unethical counterfeit consumption. Journal of Business Research. doi:http://dx.doi.org/10.1016/j.jbusres.2016.02.038

Bush, A. J., \& Hair Jr., J. F. (1985). An assessment of the mall intercept as a data collection method. Journal of Marketing Research, 22(May), 158-167.

Byrne, B. M. (2004). Testing for Multigroup Invariance Using AMOS Graphics: A Road Less Traveled. Structural Equation Modeling, 11(2), 272-300.

Cesareo, L. (2016). Discussion, Managerial Implications, Current and Future Research Counterfeiting and Piracy (pp. 59-62): Springer.

Chaudhry, P. E., Cesareo, L., \& Stumpf, S. A. (2016). Antecedents and Anti-Counterfeiting Tactics That Influence Consumer Complicity Let's Get Engaged! Crossing the Threshold of Marketing's Engagement Era (pp. 265-265): Springer.

Cheng, H. K., Sims, R. R., \& Teegen, H. (1997). To Purchase or to Pirate Software: An Empirical Study. Journal of Management Information Systems, 13(4), 49-60.

Cheung, W.-L., \& Prendergast, G. (2006a). Buyers' perceptions of pirated products in China. Marketing Intelligence \& Planning, 24(5), 446-462. 
Cheung, W.-L., \& Prendergast, G. (2006b). Exploring the Materialism and Conformity Motivations of Chinese Pirated Product Buyers. Journal of International Consumer Marketing, 18(3), 7-31.

Chow, D. C. K. (2005). Intellectual Property Protection as Economic Policy: Will China Ever Enforce its IP Laws? Congressional-Executive Commission on China (2:00 - 3:30 pm ed.). Washington DC.

Cordell, V., Wongtada, N., \& Dieschnick, R. L. (1996). Counterfeit Purchase Intentions: The Role of Lawfulness Attitudes and Product Traits as Determinants. Journal of Business Research, 35(1), 41-53.

Czellar, S. (2003). Consumer attitude toward brand extensions: an integrative model and research propositions. International Journal of Research in Marketing, 20(1), 97-115.

de Matos, C. A., Ituassu, C. T., \& Rossi, C. A. V. (2007). Consumer attitudes toward counterfeits: a review and extension. Journal of Consumer Marketing, 24(1), 36-47.

Eagly, A. H., \& Chaiken, S. (1993). The Psychology of Attitudes. Fort Worth, TX: Harcourt Brace.

Eagly, A. H., \& Chaiken, S. (1998). Attitude Structure and Function. In D. T. Gilbert, S. T. Fiske \& G. Lindzey (Eds.), The Handbook of Social Psychology (pp. 269-322). New York, NY: McGraw-Hill.

Fazio, R. H., Powell, M. C., \& Williams, C. J. (1989). The role of attitude accessibility in the attitude-to-behavior process. Journal of Consumer Research, 16(3), 280-288.

Fornell, C., \& Larcker, D. F. (1981). Evaluating Structural Equation Models with Unobservable Variables and Measurement Error. Journal of Marketing Research, 18(1), 39-50.

Grewal, R., Mehta, R., \& Kardes, F. R. (2000). The Role of Social Identity Function of Attitudes in Consumer Innovativeness and Opinion Leadership. Journal of Economic Psychology, 21(3), 233-252.

Grewal, R., Mehta, R., \& Kardes, F. R. (2004). The Timing of Repeat Purchases of Consumer Durable Goods: The Role of Functional Bases of Consumer Attitudes. Journal of Marketing Research, 41(1), 101-115.

Harvey, P. J., \& Walls, W. D. (2003). Laboratory markets in counterfeit goods: Hong Kong versus Las Vegas. Applied Economics Letters, 10(14), 883-887.

Herek, G. M. (1987). Can functions be measured? A new perspective on the functional approach to attitudes. Social Psychology Quarterly, 50(4), 285-303. 
HKCSD. (2013). Hong Kong Population Statistics. Hong Kong: The Government of Hong Kong Special Administrative Region.

Hoe, L., Hogg, G., \& Hart., S. (2003). Fakin' It: Counterfeiting and Consumer Contradictions. Paper presented at the European Advances in Consumer Research, Provo, UT.

Hogg, M. A., \& Abrams, D. (1988). Social Identifications: A Social Psychology of Intergroup Relations and Group Processes. New York, NY: Routledge.

Hu, L.-t., \& Bentler, P. M. (1999). Cutoff criteria for fit indexes in covariance structure analysis: conventional criteria versus new alternatives. Structural Equation Modeling, 6(1), 1-55.

Johar, J. S., \& Sirgy, M. J. (1991). Value expressive utilitarian advertising appeals: When and why to use which appeal. Journal of Advertising, 20(3), 23-33.

Kardes, F. R. (2002). Consideration Set Overvaluation: When Impossibly Favorable Ratings of a Set of Brands Are Observed. Journal of Consumer Psychology, 12(4), 353-361.

Katz, D. (1960). The functional approach to the study of attitudes. Public Opinion Quarterly, 24(2), 163-204.

Korgaonkar, P. K., Lund, D., \& Price, B. (1985). A structural equations approach toward examination of store attitude and store patronage behavior. Journal of Retailing, 61(2), 39-60.

Krosnick, J. A., \& Petty, R. E. (Eds.). (1995). Attitude strength: Antecedents and consequences (Vol. 4). Hillsdale, NJ: Lawrence Erlbaum Associates, Inc.

Lapinski, M. K., \& Boster, F. J. (2001). Modeling the Ego-Defensive Function of Attitudes. Communication Monographs, 68(3), 314-324.

Locander, W. B., \& Spivey, W. A. (1978). A functional approach to attitude measurement. Journal of Marketing Research, 15(4), 576-587.

Maldonado, C., \& Hume, E. C. (2005). Attitudes Toward Counterfeit Products: An Ethical Perspective. Journal of Legal, Ethical and Regulatory Issues, 8(2), 105-117.

Penz, E., \& Stöttinger, B. (2005). Forget the "Real" Thing - Take the Copy! An Explanatory Model for the Volitional Purchase of Counterfeit Products. Paper presented at the Advances in Consumer Research, Duluth, MN.

Penz, E., \& Stöttinger, B. (2008a). Corporate image and product similarity - Assessing major demand drivers for counterfeits in a multi-country study Psychology \& Marketing, 25(4), 352-381. 
Penz, E., \& Stöttinger, B. (2008b). Original brands and counterfeit brands - do they have anything in common? Journal of Consumer Behaviour, 7(2), 146-163.

Prendergast, G., Chuen, L. H., \& Phau, I. (2002). Understanding consumer demand for nondeceptive pirated brands. Marketing Intelligence \& Planning, 20(7), 405-416.

Rosenbaum, M. S., Cheng, M., \& Wong, I. A. (2016). Retail knockoffs: Consumer acceptance and rejection of inauthentic retailers. Journal of Business Research, 69(7), 2448-2455.

Schlosser, A. E. (1998). Applying the Functional Theory of Attitudes to Understanding the Influence of Store Atmosphere on Store Inferences. Journal of Consumer Psychology, 7(4), 345-369.

Sharma, P. (2011a). Country-of-Origin Effects in Developed vs. Emerging Markets: Exploring the Contrasting Roles of Materialism and Value-Consciousness. Journal of International Business Studies, 42(2), 285-306.

Sharma, P. (2011b). Demystifying Cultural Differences in Country-of-Origin Effects: Exploring the Moderating Roles of Product Type, Consumption Context, and Involvement. Journal of International Consumer Marketing, 23(5), 344-364.

Sharma, P., \& Chan, R. Y. K. (2011). Counterfeit Proneness: Conceptualization and Scale Development. Journal of Marketing Management, 27(5-6), 602-626.

Sharma, P., \& Chan, R. Y. K. (2012). Exploring Counterfeit Purchase Behavior: Towards a Unified Conceptual Framework. Paper presented at the Advances in Consumer Research - Building Connections, St. Louis, MO.

Sharma, P., \& Chan, R. Y. K. (2016). Demystifying deliberate counterfeit purchase behaviour: Towards a unified conceptual framework. Marketing Intelligence \& Planning, 34(3), 318-335.

Shavitt, S. (1989). Operationalizing functional theories of attitude. In A. R. Pratkanis, S. J. Breckler \& A. G. Greenwald (Eds.), Attitude structure and function (pp. 311-337). Hillsdale, NJ: Lawrence Erlbaum.

Shavitt, S. (1990). The role of attitude objects in attitude functions. Journal of Experimental Social Psychology, 26(2), 124-148.

Shavitt, S., Lowrey, T. M., \& Han, S.-P. (1992). Attitude functions in advertising: The interactive role of products and self-monitoring. Journal of Consumer Psychology, 1(4), 337-364.

Shavitt, S., \& Nelson, M. R. (2002). The role of attitude functions in persuasion and social judgment. In J. P. Dillard \& M. Pfau (Eds.), The persuasion handbook: Developments in theory and practice (pp. 137-153). Thousand Oaks, CA: Sage. 
Sirgy, M. J., Johar, J. S., Samli, A. C., \& Clairborne, C. B. (1991). Self-congruity versus functional congruity: predictors of consumer behavior. Journal of the Academy of Marketing Science, 19(4), 363-375.

Smith, M. B., Bruner, J. S., \& White, R. W. (1956). Opinions and Personality. New York, NY: John Wiley \& Sons.

Snyder, M., \& DeBono, K. G. (1985). Appeals to Image and Claims About Quality: Understanding the Psychology of Advertising. Journal of Personality and Social Psychology, 49(3), 586-597.

Snyder, M., \& DeBono, K. G. (1989). Understanding the Attitude Functions: Lessons from Personality and Social Behavior. In A. R. Pratkanis, S. J. Breckler \& A. G. Greenwald (Eds.), Attitude structure and function (pp. 339-359). Hillsdale, NJ: Erlbaum.

Spivey, W. A., Munson, J. M., \& Locander, W. B. (1983). Improving the Effectiveness of Persuasive Communications: Matching Message with Functional Profile. Journal of Business Research, 11(2), 257-269.

Stöttinger, B., \& Penz, E. (2015). Concurrent Ownership of Brands and Counterfeits: Conceptualization and Temporal Transformation from a Consumer Perspective. Psychology \& Marketing, 32(4), 373-391.

Teah, M., Phau, I., \& Huang, Y.-a. (2015). Devil continues to wear "counterfeit" Prada: a tale of two cities. Journal of Consumer Marketing, 32(3), 176-189.

Walthers, A., \& Buff, C. L. (2008). Attitudes Towards Counterfeiting and Counterfeit Products: Have they changed? Journal of International Business \& Economics, 8(3), 79-87.

WCO. (2014). Illicit Trade Report (pp. 110). Brussels, Belgium: World Customs Organization.

Wee, C.-H., Tan, S.-J., \& Cheok, K.-H. (1995). Non-price Determinants of Intention to Purchase Counterfeit Goods: An Exploratory Study. International Marketing Review, 12(6), 19-46.

Wheaton, B., Muthen, B., Alwin, D. F., \& Summers, G. F. (1977). Assessing reliability and stability in panel models. In D. R. Heise (Ed.), Sociological methodology (pp. 84-136). San Francisco: Jossey-Bass.

Wilcox, K., Kim, H. M., \& Sen, S. (2009). Why Do Consumers Buy Counterfeit Luxury Brands? Journal of Marketing Research, 46(2), 247-259.

Yao, V. W. (2006). An Economic Analysis of Counterfeit Goods: the Case of China.

Zampetakis, L. A. (2014). The emotional dimension of the consumption of luxury counterfeit goods: an empirical taxonomy. Marketing Intelligence \& Planning, 32(1), 21-40. 
Figure 1 - Basic conceptual framework

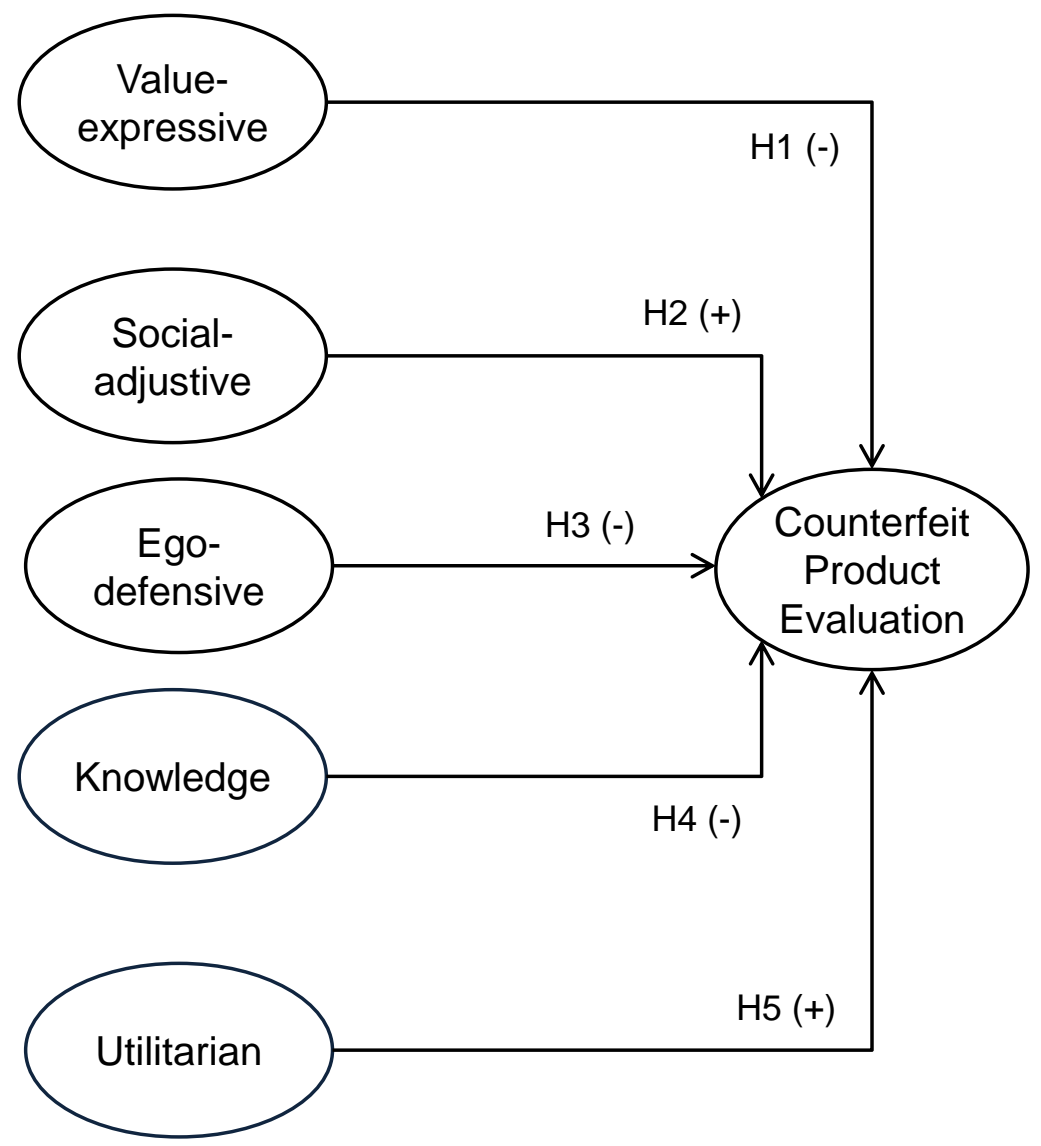


Figure 2 - Extended Conceptual framework

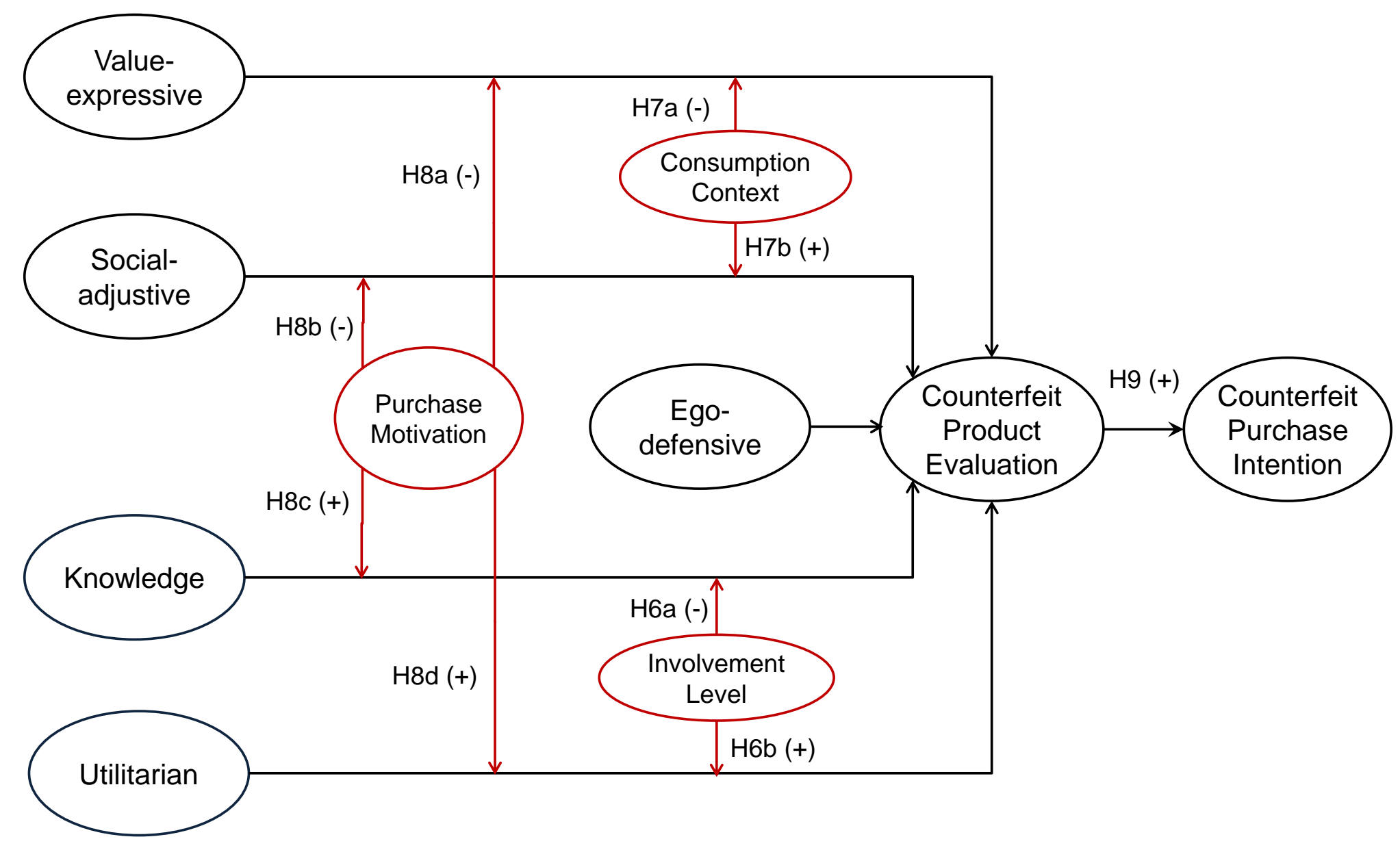


Table 1 - Sample profile

\begin{tabular}{|c|c|c|c|c|c|}
\hline \multirow[b]{2}{*}{ Demographics } & \multirow{2}{*}{$\begin{array}{l}\text { Overall } \\
(\mathrm{N}=\mathbf{8 9 0})\end{array}$} & \multicolumn{4}{|c|}{ Product Categories } \\
\hline & & $\begin{array}{c}\text { Watch } \\
(\mathrm{N}=229) \\
\end{array}$ & $\begin{array}{c}\text { Software } \\
(\mathrm{N}=\mathbf{2 4 3})\end{array}$ & $\begin{array}{c}\text { DVD } \\
(\mathrm{N}=229)\end{array}$ & $\begin{array}{c}\text { Backpack } \\
(\mathrm{N}=189)\end{array}$ \\
\hline \multicolumn{6}{|l|}{ Gender } \\
\hline Female & $471(53 \%)$ & $124(54 \%)$ & $128(53 \%)$ & $118(52 \%)$ & $107(57 \%)$ \\
\hline Male & $419(47 \%)$ & $105(46 \%)$ & $115(47 \%)$ & $111(48 \%)$ & $82(43 \%)$ \\
\hline \multicolumn{6}{|l|}{ Age } \\
\hline$\leq 20$ & $253(28 \%)$ & $46(20 \%)$ & $92(38 \%)$ & $69(30 \%)$ & $46(24 \%)$ \\
\hline $21-30$ & $371(42 \%)$ & $90(39 \%)$ & $73(30 \%)$ & $105(46 \%)$ & $103(54 \%)$ \\
\hline $31-40$ & $150(17 \%)$ & $46(20 \%)$ & $36(15 \%)$ & $43(19 \%)$ & $25(13 \%)$ \\
\hline $41-50$ & $68(08 \%)$ & $33(14 \%)$ & $18(07 \%)$ & $8(03 \%)$ & $9(05 \%)$ \\
\hline$>50$ & $17(02 \%)$ & $5(02 \%)$ & $4(02 \%)$ & $3(01 \%)$ & $5(03 \%)$ \\
\hline \multicolumn{6}{|l|}{ Education level } \\
\hline High school or less & $247(28 \%)$ & $79(34 \%)$ & $60(25 \%)$ & $75(33 \%)$ & $33(17 \%)$ \\
\hline College/University & $422(47 \%)$ & $88(38 \%)$ & $106(44 \%)$ & $121(53 \%)$ & $107(57 \%)$ \\
\hline Postgraduate degree & $133(15 \%)$ & $32(14 \%)$ & $53(22 \%)$ & $19(08 \%)$ & $29(15 \%)$ \\
\hline Others & $88(10 \%)$ & $30(13 \%)$ & $24(10 \%)$ & $14(06 \%)$ & $20(11 \%)$ \\
\hline \multicolumn{6}{|l|}{ Occupation } \\
\hline Blue Collar & $124(14 \%)$ & $33(14 \%)$ & $37(15 \%)$ & $35(15 \%)$ & $19(10 \%)$ \\
\hline White Collar & $387(43 \%)$ & $118(52 \%)$ & $128(53 \%)$ & $85(37 \%)$ & $56(30 \%)$ \\
\hline Students & $268(30 \%)$ & $56(24 \%)$ & $42(17 \%)$ & $87(38 \%)$ & $83(44 \%)$ \\
\hline Others & $111(12 \%)$ & $22(10 \%)$ & $36(15 \%)$ & $22(10 \%)$ & $31(16 \%)$ \\
\hline \multicolumn{6}{|c|}{ Past Counterfeit Purchase (Ever) } \\
\hline No & $342(38 \%)$ & $117(51 \%)$ & $72(30 \%)$ & $61(27 \%)$ & $92(49 \%)$ \\
\hline Yes & $548(62 \%)$ & $112(49 \%)$ & $171(70 \%)$ & $168(73 \%)$ & $97(51 \%)$ \\
\hline \multicolumn{6}{|c|}{ Counterfeit Purchase Frequency (Past 3 Months) } \\
\hline None & $589(66 \%)$ & $152(66 \%)$ & $167(69 \%)$ & $146(64 \%)$ & $124(66 \%)$ \\
\hline 1-2 Times & $284(32 \%)$ & $75(33 \%)$ & $67(28 \%)$ & $80(35 \%)$ & $62(33 \%)$ \\
\hline$>2$ Times & $17(02 \%)$ & $2(01 \%)$ & $9(04 \%)$ & $3(01 \%)$ & $3(02 \%)$ \\
\hline
\end{tabular}


Table 2 - Scale items (psychometric properties)

\begin{tabular}{l}
\hline Scale Items (Psychometric Properties) \\
\hline Ego-defensive Function (AED)
\end{tabular}

1. Using a <Product> helps me enhance my self-esteem.

2. Using a <Product $>$ helps me boost my self-confidence.

3. Using a $<$ Product $>$ helps me protect my self-image.

4. I feel proud using a <Product>.

Knowledge Function (AKN)

5. I would buy a <Product> because I want to know more about it.

6. Using a $<$ Product $>$ shows that I know a lot about $<$ Product $>$ s.

7. I can distinguish between a genuine and a fake $<$ Product>.

8. I am quite knowledgeable about <Product $>$ s.

Social-adjustive Function (ASA)

9. I consider a <Product> a symbol of social status.

10. Using a $<$ Product $>$ would help me fit into important social situations.

11. I would like to be seen using a <Product>.

12. I would make a good impression on others by using a $<$ Product $>$.

Utilitarian Function (AUT)

13. For me a <Product> is just like any other <Product $>$.

14. I think a $<$ Product $>$ is as good as most other $<$ Product $>$ s.

15. I do not consider a <Product> good value-for-money.

16. I consider a <Product> an inexpensive object.

\section{Value-expressive Function (AVE)}

17. A <Product> would reflect the kind of person I see myself to be.

$\lambda \quad C R=.82$

$\alpha$

.80

.69

$.83 \quad .72$

.70

$3.17 \quad 1.66$

.81

.67

$3.14 \quad 1.63$

.78

$C R=.80$

$A V E=.55$

$3.18 \quad 1.71$

.71

.53

$3.49 \quad 1.30$

.75

.57

$3.43 \quad 1.61$

.72

.72

.54

$3.34 \quad 1.55$

.78

.60

$3.67 \quad 1.69$

$C R=.84 \quad A V E=.66$

$3.51 \quad 1.61$

.80

.64

$3.33 \quad 1.45$

.75

.56

$3.36 \quad 1.78$

.84

.71

$3.41 \quad 1.67$

.86

.74

$3.26 \quad 1.60$

$C R=.81 \quad A V E=.56 \quad 4.18 \quad 1.08$

.78

.61

$4.20 \quad 1.52$

.75

.58

$4.34 \quad 1.41$

.73

.72

.56

$4.13 \quad 1.46$

18. A < Product> would help me communicate my selfidentity.

$$
C R=.83 \quad A V E=.67 \quad 3.46 \quad 1.52
$$

.85

.72

$3.60 \quad 1.64$

19. A < Product> would help me express myself.

.81

.67

$3.46 \quad 1.67$

20. A < Product> would help me define my personality.

Counterfeit Proneness (CFP)

.79

.59

$3.36 \quad 1.66$

.82

.68

$3.41 \quad 1.70$

$C R=.85 \quad A V E=.63 \quad 2.81 \quad 1.28$ 
1. Buying counterfeit products makes me feel good.

.81

.83

2. I feel excited when buying counterfeit products.

3. When I buy counterfeit products, I feel that I am getting a good deal.

4. I enjoy buying counterfeits, regardless of the money I save by doing so.

5. Many of the branded products that I have are counterfeits.

6. Counterfeits enable me to own brands that I normally would not buy.

\section{Subjective Norms (SUB)}

7. I think no one will mind if I buy this fake <Product>.

8. I think everyone will consider it a smart decision if I buy this fake <product>.

9. I think everyone would like me to buy this fake $<$ Product>.

\section{Ethical Judgments (ETH)}

10. I think buying this fake <Product> would be immoral. *

11. I think buying this fake <Product> would be unethical. *

12. I think buying this fake <Product> would be illegal. *

13. I think buying this fake<Product> would be wrong. *

Product Evaluation (CPE)

14. I think this fake <Product> looks as good as a genuine $<$ Product>.

15. I think this fake <Product $>$ will work as good as a genuine $<$ Product $>$.

16. I think this fake $<$ Product $>$ will last as long as a genuine $<$ Product>.

\section{Purchase Intention (CPI)}

17. I would not mind buying this fake <Product>.

18. I think buying this fake <Product> would be a smart decision.

19. I would love to buy this fake <Product>.

20. I will have no hesitation in buying this fake <Product>.

.86

.80

80

.73

.73

.73

\section{CR}

.87

.75

.75

.82

.72

.79

.78

.86

.85

.80

.82

.81

.88

.74

.84

.64

.66

3.04

1.49

.69

$2.82 \quad 1.51$

.74

2.92

1.59

.53

$2.72 \quad 1.53$

$C R=.82$

.53

2.84

1.65

$C R=.84 \quad A V E=.66$

3.32

1.35

$3.39 \quad 1.53$

.76

$3.33 \quad 1.52$

.52

3.23

1.51

.64

3.58

1.23

.51

$3.62 \quad 1.42$

.62

$3.65 \quad 1.42$

.60

$3.46 \quad 1.52$

.75

$3.58 \quad 1.44$

$C R=.85 \quad A V E=.68$

3.65

1.43

.74

$3.65 \quad 1.55$

.70

$3.69 \quad 1.54$

.72

$3.60 \quad 1.59$

$C R=.86 \quad A V E=.67$

$3.40 \quad 1.17$

.65

$3.69 \quad 1.74$

.78

$3.43 \quad 1.67$

.59

$3.25 \quad 1.64$

.70

$3.22 \quad 1.68$

$\chi_{(496)}^{2}=864.27 ; \chi^{2}$ ldf $=1.74 ; G F I=.95 ; N F I=.96 ; C F I=.97 ; R M S E A=.030$, SRMR $=.036$

Note: $\lambda$ : Standardized factor loadings, $\alpha$ : Squared multiple correlations;

CR: Composite reliability; AVE: Average variance extracted; * Reverse-worded items 
Table 3 - Correlations matrix

\begin{tabular}{|c|c|c|c|c|c|c|c|c|c|c|}
\hline Ego-defensive Function (AED) & - & & & & & & & & & \\
\hline Social-adjustive Function (ASA) & $.42^{* * *}$ & $.36^{* * *}$ & - & & & & & & & \\
\hline Utilitarian Function (AUT) & .03 & $.15^{* *}$ & .02 & - & & & & & & \\
\hline Counterfeit Proneness (CFP) & $.31^{* * *}$ & $.42^{* * *}$ & $.31^{* * *}$ & .07 & $.29^{* * *}$ & - & & & & \\
\hline Ethical Judgment (ETH) & -.03 & -.06 & -.06 & $-.26^{* * *}$ & -.06 & $.30^{* * * *}$ & - & & & \\
\hline Subjective Norms (SUB) & $.13^{* *}$ & $.36^{* * *}$ & $.12^{* *}$ & -.02 & $.12^{* *}$ & $.25^{* * *}$ & $.34^{* * *}$ & - & & \\
\hline Product Evaluation (CPE) & $-.10^{*}$ & $.08^{*}$ & $-.12^{* *}$ & .06 & $-.14^{* *}$ & $.35^{* * *}$ & $.32^{* * *}$ & $.26^{* * *}$ & - & \\
\hline
\end{tabular}


Table 4 - Hierarchical regression output

\begin{tabular}{|c|c|c|c|c|c|c|c|}
\hline Нуро\# & Independent Variables & $\begin{array}{c}\text { Model } 1 \\
\text { DV: CPE }\end{array}$ & $\begin{array}{l}\text { Model } 2 \\
\text { DV: CPE }\end{array}$ & $\begin{array}{l}\text { Model } 3 \\
\text { DV: CPE }\end{array}$ & $\begin{array}{l}\text { Model } 4 \\
\text { DV: CPI }\end{array}$ & $\begin{array}{l}\text { Model } 5 \\
\text { DV: CPI }\end{array}$ & Result \\
\hline H1 (-) & Value-expressive (AVE) & - & $-.24^{* * * *}$ & $-.17^{* *}$ & $-.19^{* *}$ & .10 & Supported \\
\hline $\mathrm{H} 2(+)$ & Social-adjustive (ASA) & - & $-.61^{* * * *}$ & $-.41^{* * * *}$ & $-.37^{* * * *}$ & $-.21^{* *}$ & Not supported \\
\hline H3 (-) & Ego-defensive (AED) & - & $-.15^{* *}$ & $-.14^{* *}$ & $-.16^{* *}$ & -.09 & Supported \\
\hline H4 (-) & Knowledge (AKN) & - & $-.21^{* *}$ & $-.13^{*}$ & $-.18^{* *}$ & $-.11^{*}$ & Supported \\
\hline $\mathrm{H} 5(+)$ & Utilitarian (AUT) & - & $.32^{* * * *}$ & $.10^{*}$ & $.13^{* *}$ & .07 & Supported \\
\hline H6a (-) & $\mathrm{INV} * \mathrm{AKN}$ & - & - & $-.24^{* * *}$ & $-.27^{* * * *}$ & $-.13^{*}$ & Supported \\
\hline $\mathrm{H} 6 \mathrm{~b}(+)$ & INV*AUT & - & - & $.14^{*}$ & $.18^{* *}$ & .08 & Supported \\
\hline H7a (-) & $\mathrm{CON}^{*} \mathrm{AVE}$ & - & - & $-.26^{* * *}$ & $-.29^{* * * *}$ & $-.16^{* *}$ & Supported \\
\hline $\mathrm{H} 7 \mathrm{~b}(+)$ & CON*ASA & - & - & $.11^{* *}$ & $.14^{* *}$ & .06 & Supported \\
\hline H8a (-) & MOT*AVE & - & - & .08 & $.12^{*}$ & .08 & Not supported \\
\hline H8b (-) & MOT*ASA & - & - & $-.19^{* *}$ & $-.21^{* *}$ & -.09 & Supported \\
\hline $\mathrm{H} 8 \mathrm{c}(+)$ & $\mathrm{MOT}^{*} \mathrm{AKN}$ & - & - & $-.11^{*}$ & $-.13^{* *}$ & -.05 & Not supported \\
\hline H8d (+) & MOT*AUT & - & - & $.28^{* * *}$ & $.32^{* * *}$ & $.18^{* *}$ & Supported \\
\hline \multirow[t]{2}{*}{ H9 (+) } & Product evaluation (CPE) & - & - & - & - & $.48^{* * * *}$ & Partial support \\
\hline & Control Variables & & & & & & \\
\hline $\mathrm{C} 1$ & Counterfeit proneness (CFP) & $.27^{* * *}$ & $.22^{* * *}$ & $.18^{* *}$ & $.21^{* *}$ & $.12^{*}$ & \\
\hline $\mathrm{C} 2$ & Ethical judgment (ETH) & $.23^{* * *}$ & $.19^{* *}$ & $.16^{* *}$ & $.20^{* *}$ & .10 & \\
\hline $\mathrm{C} 3$ & Subjective norms (SUB) & $.28^{* * *}$ & $.25^{* * *}$ & $.22^{* * * *}$ & $.24^{* * * *}$ & $.15^{* *}$ & \\
\hline $\mathrm{C} 4$ & Involvement (INV) & $.17^{* *}$ & $.14^{*}$ & $.11^{*}$ & $.13^{* *}$ & .06 & \\
\hline $\mathrm{C} 5$ & Consumption context $(\mathrm{CON})$ & $-.23^{* * *}$ & $-.21^{* * * *}$ & $-.20^{* * * *}$ & $-.22^{* * * *}$ & -.10 & \\
\hline \multirow[t]{2}{*}{ C6 } & Purchase motivation (MOT) & $.09^{*}$ & .07 & .04 & $.11^{*}$ & .01 & \\
\hline & Adjusted R-squared Value & .05 & .13 & .30 & .36 & .42 & \\
\hline
\end{tabular}

